\title{
Moisture gradients form a vapor cycle within the viscous boundary layer as an organizing principle to worker termites
}

\author{
R. Soar ${ }^{1}$ (I) G. Amador ${ }^{2} \cdot$ P. Bardunias ${ }^{3} \cdot$ J. S. Turner $^{4,5}$
}

Received: 20 October 2017 / Revised: 5 October 2018 / Accepted: 11 October 2018 / Published online: 8 November 2018

(c) The Author(s) 2018

\begin{abstract}
Studies of termite mound building have considered the mud they prepare, its properties and its composition. Here we consider the behaviors of the mound building termites Macrotermes michaelseni, (Sjostedt), in the presence of the viscous boundary layer (VBL), which spontaneously forms over any surface that air passes over. We looked how soil moisture and air vapor are coupled to form a feedback loop and a spatiotemporal precursor to worker termites in the presence of mound material. We explored residency and activities of workers when presented with a VBL and either varying substrate temperature gradients or a soil moisture transition within the soil substrate. We report the emergence of a 'vapor conveyor', which forms around a neutral evaporative equilibrium point (NEEP) at the soil/air interface, where the soil-borne moisture temperature (along the gradient) and the $100 \%$ saturated air-borne vapor temperature coincide within the VBL, forming a bubble of neutral mass transfer which, we propose, worker termites are sensitive to as viscosity changes within. We found, on average, that $67 \%$ (std. dev 27\%) of behavioral events (clustering, excavation, and deposition) occurred within $1{ }^{\circ} \mathrm{C}$ either side of the NEEP. We found negative correlation $(-0.78)$ between the substrate temperature gradient $\left(0.1-0.9{ }^{\circ} \mathrm{C} \mathrm{mm}^{-1}\right)$ and the extents of behavioral activity, suggesting coupling between soil-borne moisture and air-borne vapor advection within the VBL. We recorded unique behaviors relating to interaction with the viscosity of vapor-saturated air at this scale. We speculate that workers may exploit the VBL to overcome a classic trade-off, i.e., how to push activities forward into potentially desiccating environments while conserving moisture in both the termites and the soil they build with.
\end{abstract}

Keywords Worker termite behavior $\cdot$ Construction $\cdot$ Viscous boundary layer $\cdot$ Moisture gradient $\cdot$ Spatiotemporal precursor · Template

\section{Introduction}

The concept of stigmergy, developed by Grassé in 1959 (Theraulaz and Bonabeau 1999), provided a chemoreception model for social insect construction which can be summarized as 'deposition leading to further deposition'. Though reinforced by early computational simulations, within emerging swarm robot models its definition is broader as 'a mechanism of indirect coordination in which a trace is left by an action in a medium [that] stimulates subsequent actions' (Heylighen 2016). In mound building termites,

Electronic supplementary material The online version of this article (https://doi.org/10.1007/s00040-018-0673-0) contains supplementary material, which is available to authorized users.

R. Soar

rupert.soar@ntu.ac.uk

Extended author information available on the last page of the article where evidence exists for sensitivity to evaporative components (namely, pheromones) as an organizing principle around the queen and during trail following, a building pheromone, per se, has proved elusive.

Some assumptions for its existence come from Bruinsma's PhD study (Bruinsma et al. 1979) and some question the interpretation of the research in the face of growing evidence that alternative factors may work as effectively as a chemical based 'build pheromone'. Bardunias et al. have considered thigmotaxis in termites (Lee et al. 2008), the perception of tactile cues in excavation (Bardunias and $\mathrm{Su}$ 2010) and the accumulation of depositions as a peripheral effect near excavation sites (Green et al. 2017). Turner (2011) proposed a role for soil moisture as a potential stigmergic cue for building behavior when comparing Macrotermes natalensis and Macrotermes michaelseni mounds in Namibia, concluding "the building behavior of Macrotermes michaelseni [workers] appears to be more strongly 
driven by water, and has a stronger tendency to move soil and water along gradients from wet to dry. Building behavior of Macrotermes natalensis, in contrast, appears to be more confined by a greater reliance on cement pheromone to organize building".

Fouquet et al. (2014) explored termite worker selection between sites of 'marked and textured' sources of material, concluding that the existing structure or texture was a strong cue, over 'volatile marking', even though they acknowledged that better control of evaporative effects was lacking.

Worker termites masticate soil and water to create mud, as a subtle and complex combination of moisture and granular materials. Jouquet et al. (2002) explored the preference of worker termites to soils, observing complex decisions when selecting aggregates and clays for differing structures, noting "the kinetics of water retention reveals the ability of each soil to hold and to exchange water with the outside environment", inferring that termites are not selecting construction materials based on a specific property, beyond how granular materials behave in the presence of water. Murthy et al (Kandasami et al. 2016; Zachariah et al. 2017) extended studies of termite soil properties in India, observing that workers modulate the water content of a mud bolus between the liquid and plastic Atterberg limits, i.e., the point of optimum 'workability' or 'buildability'.

Here we expand the concept of moisture stigmergy, as a spatiotemporal precursor to worker termites in the presence of mound material and moisture gradients. We consider the role of soil moisture and evaporation equilibrium at the soil/ air interface, at the scale of worker termites interacting with the medium of mud. Specifically we explore the presence and role of the viscous boundary layer (VBL), as a physical constraint and mechanism of feedback to workers.

When airflows over a surface, gradients in the physical properties of the air, such as velocity, humidity and heat, form at the interface. Gradients arise from airflow interacting with solid surfaces and structures, such as the ground and insects, which collectively are termed the viscous boundary layer (VBL) (Prandtl 1904; Blasius 1908). Within the VBL, velocity, mass transfer and thermal properties are coupled as gradients of viscous dissipation, which persist as thin layers surrounding solid-air interfaces.

Termites, in particular worker termites, exist within a low Reynolds ( $\mathrm{Re}$ ) number domain within the boundary layer. The Reynolds number defines the relationship between inertia and viscosity dominated conditions, which define laminar and turbulent flows as viscosity changes occur. In general, the VBL can be expressed as $\delta=5.0 x \operatorname{Re}_{x}^{-1 / 2}$, where $R e_{x}=\rho U x \mu^{-1}$ is the Reynolds number with respect to the length $x$ along the solid surface for a fluid with density $\rho$, viscosity $\mu$, and freestream velocity $U$. At the scale of an insect within the VBL, air is not fully viscous, as defined by 'Stokes flow' $(R e \leq 1)$, it is simply 'more viscous' $(\operatorname{Re}<10)$. There is inertia, but viscosity and changes in viscosity are perceptible to individual insects (Cooter and Baker 1977).

Within the VBL and at this scale, molecules reach sensors predominantly by diffusion, which is slow. Antennae for example, as dense arrays of fibers, create a resistance to airflow and elevate chemo-sensors into faster moving air above the VBL (Vogel 1983; Vogel 2004; Loudon and Koehl 2000; Schneider et al. 1998).

Insects exist at the interface of liquid and vapor domains. Within a closed system, the term evaporative equilibrium describes the movement of water molecules between the liquid and vapor phase, up to the point the air becomes saturated, where no further change in vapor pressure, density or liquid temperature will occur. In reality, the VBL is a quasi-closed system, where molecular diffusion rates are limited and slower, compared to faster convection rates at larger scales, and because airflow moves parallel to the interface, vapor is moving along the interface by advection. A moist soil/air interface is not a liquid/vapor interface. Moisture is retained through capillary and matric forces within a porous structure, where solid/liquid/vapor phases exist in close proximity. Moist soil surfaces sustain a thicker interface between liquid and vapor phases, depending on the temperature and vapor pressure within the VBL (Zhou and Han 2013; Alvenas and Jansson 1997).

Assuming the VBL's saturated vapor pressure is below evaporative equilibrium, it is free to accept moisture from a moist surface. Inversely, where the VBL's vapor pressure is saturated and encounters a dry or cool surface, it will give up moisture back to the soil. Figure 1a considers an airflow, where (1) the VBL forms over a moist soil substrate, (2) a temperature or moisture gradient exists within the soil substrate, (3) the warm or wet end of the gradient is upstream of the airflow and the cool or dry end is downstream, and (4) the mid-point of the gradient coincides with the neutral evaporative equilibrium point (NEEP). We define the NEEP as the point along the gradient, where neither evaporation nor condensation occurs at the interface, this point being at evaporative equilibrium, because the temperature of the substrate coincides with the temperature of the air above it is at $100 \%$ vapor saturation. Upstream of the NEEP, a net evaporative condition (i.e., a positive vapor forcing to the VBL) exists, which inverts to a net condensing condition (i.e., negative vapor forcing from the VBL) downstream.

The combination of the gradient, the direction of airflow, the scale and the ability of the VBL to accept moisture, means that soil moisture will evaporate (as vapor) ahead of the NEEP, move over the NEEP (as advection), and condense vapor (as moisture) behind it. Whether the substrate gradient is one of heat or moisture, there will be a normalizing of the gradient around the NEEP. In the absence of termites, the region of vapor conveyance will 


\section{The Vapor Convevor}

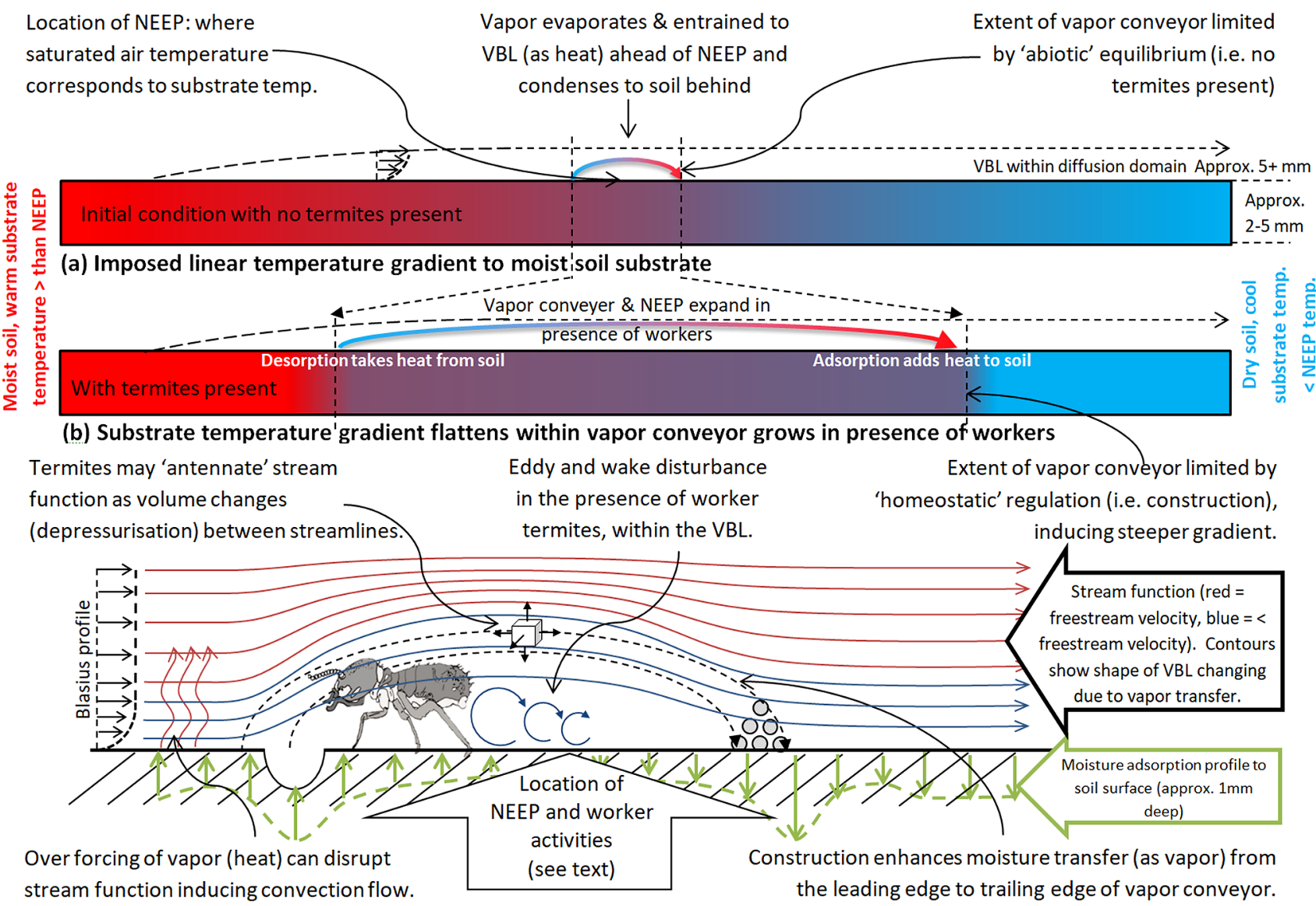

(c) Effect of vapor transfer (to and from soil substrate) to stream function and shape of the VBL

Fig. 1 a 'Vapor conveyor' emerges at the soil/air interface, either side of a neutral evaporative equilibrium point (NEEP) due to the presence of (i) temperature gradient, (ii) moist soil substrate and (iii) diffusion limited viscous boundary layer. It expands around the NEEP and its extents are limited by 'abiotic equilibrium' (vertical dashed line). b Workers sense the vapor conveyor as it is coupled to soil moisture and

expand to an abiotic equilibrium limit, where there is no additional source of energy to drive and expand the conveyor further.

Figure $1 \mathrm{~b}$ considers the intervention of worker termites assuming, as this research set out to explore, that they are sensitive to the phase transition of soil moisture and its conveyance within the VBL. Both excavation and deposition are topological folding and increases moisture exchange between the soil substrate and VBL. Excavation and deposition input additional energy which expands the 'vapor conveyor' to a homeostatic equilibrium limit, regulated by the actions of the worker termites. Theoretically, as the zone around the NEEP expands, then the substrate temperature within the vapor cycle will converge to that of the VBL air temperature at $100 \%$ saturation. Outside the limits of the vapor conveyor the substrate temperature gradient steepens 'workability'. Theoretically worker activities modify the vapor forcing and feedback within the VBL, where both the region of activity and the vapor cycle expand to fall within 'homeostatic equilibrium'. c Research suggests that insects sense the stream function as fine scale viscosity variation within the VBL, whose thickness varies as a function of vapor transfer to and from the soil substrate

to drive greater positive and negative vapor forcing and greater feedback to the actions of workers within.

If correct, we should see workers active within a relatively small region which gradually expands through time, to extend a region of 'stable' saturated air. The analogy is one of sustaining a vapor bubble or halo, theoretically protecting workers from the desiccating effects of pushing their activities into new regions.

Figure 1c considers the effect of vapor mass transfer to the VBL. Research by Amador et al. (2015) looked at how insects affect the 'stream function' or 'streamlines' of airflow around them. Streamlines are the paths which air molecules (or other entrained molecules) follow when flowing, and the stream function describes their distribution within the flow. It is unclear whether insects detect gradients or differences in pressure (as volumetric change) or viscosity. 
Vapor transfer will induce both thickening and thinning of the VBL and change its viscosity. The interaction of worker termites, active within the viscous medium of the VBL, will produce 'wake' and 'eddy' phenomena that may reveal relationships between both.

We exposed worker termites to a substrate of mound material with different temperature and moisture gradients between runs, analogous to conditions found between the inside and outside of the mound, and we report the location, residency and category of worker activities through each run in relation both the gradient and the location of the predicted NEEP and the vapor cycle forming around it.

\section{Methods}

Field experiments were conducted at the Cheetah View Farm near Ojtiwarongo [20³4'32.1"S 16 $\left.53^{\prime} 21.0^{\prime \prime} \mathrm{E}\right]$ in Namibia during May and June 2016. Access to the site and research permissions was provided by the private owners of the Cheetah Conservation Fund, Namibia. Worker termites used in the study were collected from mounds close to the laboratory, using $1000 \mathrm{~mm}$ lengths of $100 \mathrm{~mm}$ diameter pipe inserted into the skin of a mature mound in the evening, prior to experiments the next day. Workers build within the pipes overnight. Pipes were collected and sealed. Prior to runs, workers were tipped from the pipe onto trays, along with mound material. Soil was separated and prepared for the arena. Workers were placed in sealed plastic containers with soil and moist cellulose cloth. Workers were collected from here, placed in the arena, then returned to the container. After 2-3 h, termites and soil were returned to the location, where the pipe had been withdrawn from the mound.

\section{The arenas}

An acrylic enclosure, in Fig. 2a, of $350 \mathrm{~mm} \times 60 \mathrm{~mm} \times$ $60 \mathrm{~mm}$, sustained a balanced (via a Cole Palmer 0.1-0.5 L $\mathrm{min}^{-1}$ mass/flow regulator) and regulated airflow over a single trough of moist mound soil (240 mm long $\times 15 \mathrm{~mm}$ wide $\times 6 \mathrm{~mm}$ deep). From Fig. 2a, b, capillary tubes $(1.95 \mathrm{~mm}$ (OD) $/ 1.1 \mathrm{~mm}$ (ID) $\times 100 \mathrm{~mm}$ long) were located at both the inlet and outlet end of the enclosure to a height of $10 \mathrm{~mm}$ above the substrate, producing laminar airflow. An air velocity of $5 \mathrm{~mm} \mathrm{~s}^{-1}( \pm 2)$ minimized turbulence around both worker termites and sites of excavation and deposition and produced a viscous boundary layer (VBL) at the soil/air interface. Streamline displacement and eddy vortices will still occur around workers and sites of excavation and deposition, within the VBL. The airflow rate sustained diffusion limited advection along the VBL.

Figure $2 \mathrm{c}$ shows a $1 \mathrm{~L}$ pot of $\mathrm{CaO}$ desiccant which provided a constant $10 \%$ relative humidity $(\mathrm{RH})$ to the inlet air supply. Calibrated Vaisala HMP110 RH and temperature (T) sensors were located within the inlet and outlet airflow stream (outside the arena) to (1) monitor the inlet airflow RH/T to track the critical VBL air temperature that corresponds to the substrate temperature for a NEEP to emerge, and (2) to compare the inlet to the outlet RH/T as a measure of change in mass transfer of moisture, either to or from the soil trough, as air passed through the arena. $\mathrm{RH} / \mathrm{T}$ measurements were captured at $1 \mathrm{~min}$ intervals.

An array of $6 \times 1 \mathrm{~mm}$ (ID) hypodermic needles, in Fig. 2e, were set behind the inlet capillary array to provide injection sites for polyethylene glycol (PEG) vapor. PEG vapor could be selectively injected into the laminar flow as pulses or continuous streamlines of vapor, which could visualized using a Blau $25 \mathrm{~mW}$ planar laser, set parallel to the soil surface (shone from outside of the arena). PEG vapor is slightly more dense than air and tends to sink if injected into air above a convection driven buoyancy threshold. By injecting a bolus of PEG vapor $(\approx 50 \mathrm{~mL})$ faster than the laminar airstream rate $\left(>5 \mathrm{~mm} \mathrm{~s}^{-1}\right)$, the vapor descended to the soil substrate and became entrained in air moving within the VBL, allowing us to see what was happening at the soil/air interface. Inversely, by injecting the PEG slower $\left(<5 \mathrm{~mm} \mathrm{~s}^{-1}\right)$, the molecular ratio reduces, allowing vapor to be carried by the freestream flow passing over the VBL. This allowed us to explore both the conditions in the VBL and the conditions in the freestream flow above the VBL. Figure $2 \mathrm{~d}$ shows an image enhancement of two PEG bolii (highlighted green) released into the freestream flow set to $30 \mathrm{~mm} \mathrm{~s}^{-1}$ (faster than the experimental flow of $5 \mathrm{~mm} \mathrm{~s}^{-1}$ ). There is no moist soil substrate and the three images, taken at $3 \mathrm{~s}, 6 \mathrm{~s}$ and $9 \mathrm{~s}$, which show coherence as the two bolii progress from the inlet (left) to outlet (right) of the arena.

In a prototype study, prior to this study, we considered worker sensitivity to PEG vapor injection, as this could potentially influence behavior. On encountering PEG vapor some workers appear oblivious to its presence, whereas others will stop, then sense (antennate the viscosity transition) and enact a sharp forward/reverse action (like a 'sneeze' - in human terms). Some reacting workers will move to other workers and communicate, while others will move to track along the edge of the vapor transition. Workers also do this when there is no PEG vapor present, i.e., a sharp transition exists (of viscosity or momentum) in the air around them. As a rule, we applied PEG vapor visualization of the vapor conveyor to half the runs, at the end of each run (av. minute $50 \pm 10$ ). Figure $2 \mathrm{~g}$ shows one of the methods to establish the extents of the vapor conveyor using reflectance of white light on the soil substrate. At the inlet the net evaporating condition produces low reflectance, which extends to encompass workers. A vertical white line indicates the point at which vapor condenses back to the substrate from the 

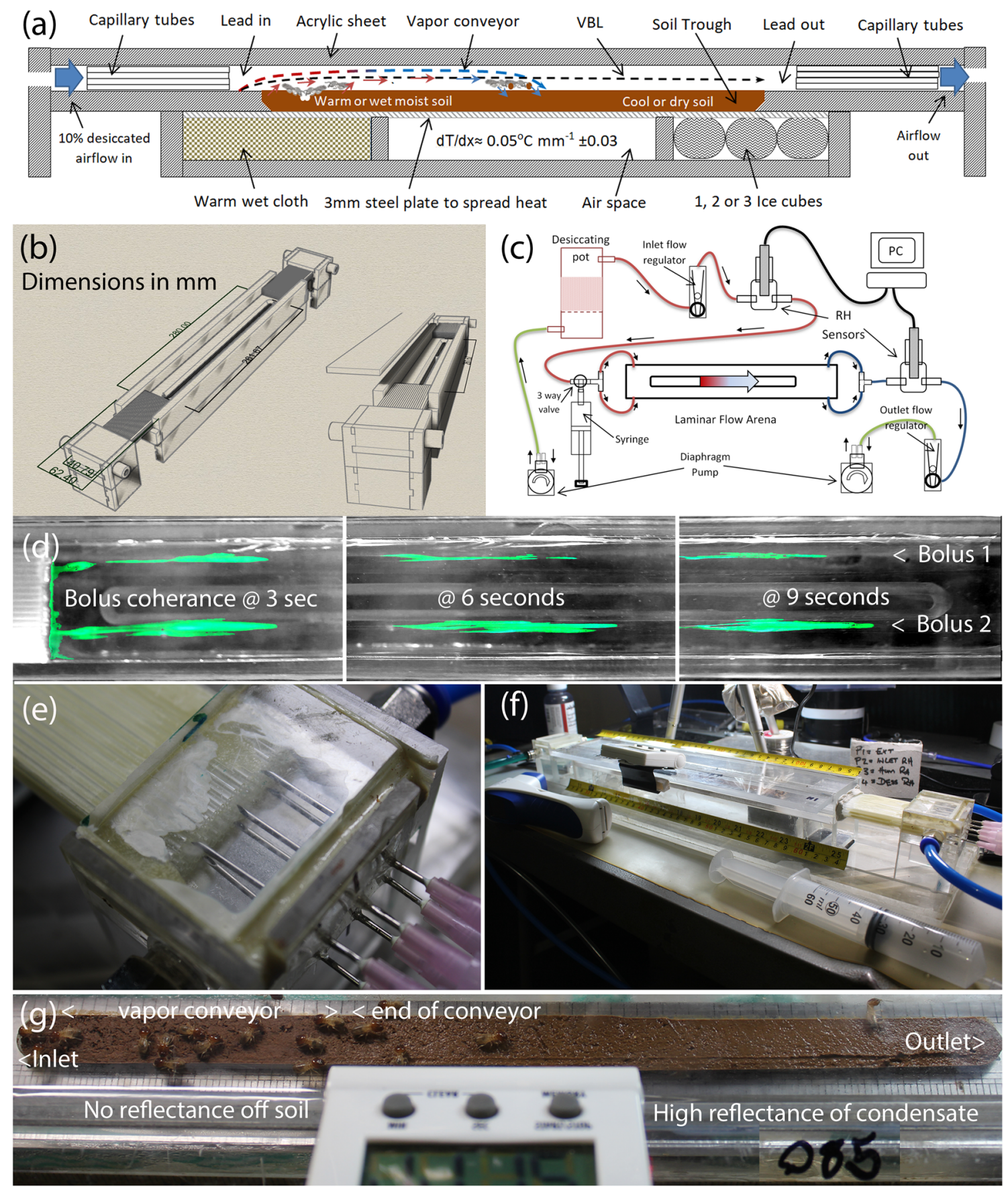

Fig. 2 a, b Schematic of laminar flow arena. c Equipment setup showing inlet air modification (10\%RH), balanced (inlet/outlet) airflow and location of $2 \times$ Vaisala humidity sensors for overall mass transfer. The inlet flow supported injection $(<50 \mathrm{ml})$ of PEG vapor for boundary layer illumination. d Planar laser illuminated twin PEG vapor bolus release shows laminar flow down the arena. e $2 \times 3$ injec-

VBL, showing high reflectance and indicating the end of the vapor conveyor.

Cohorts (av.22 \pm 10 ) of randomly mixed Macrotermes michaelseni major and minor workers, were harvested from mounds as described. 14 runs were filmed for $60 \mathrm{~min}$ with tor array for PEG vapor abutted to inlet capillary array. f Final setup with infrared temperature measuring and PEG vapor injection syringe visible. g Location and extent of vapor conveyor with visible 'reflectance' of condensate on the surface of the soil, workers are active within vapor conveyor

varying temperature and moisture gradients. The soil used was the same 'fresh build' from which workers were drawn. Murthy et al (Kandasami et al. 2016), established that Odontotermes obessus worker termites in India modulate water to soil ratios between the Atterberg plastic and liquid limits 
of $17 \%$ and $33 \%$, respectively. We established the Atterberg limits of the soil source being between $15-20 \% \mathrm{H}_{2} \mathrm{O}$ by weight for the plastic limit and $38-40 \% \mathrm{H}_{2} \mathrm{O}$ by weight for the liquid limit.

To fill the soil trough and arrive at a moisture content between the Atterberg plastic and liquid limits, we first blended water to harvested mound material to a 'fluid paste' consistency (i.e., a low shear response to displacement), close to the liquid limit, so that it could be extruded into the soil trough through a $10 \mathrm{~mm}$ diameter nozzle attached to an 'icing bag'. We levelled the paste by drawing and gently oscillating a sharp blade over the trough to level it to the acrylic baseplate. We then placed a two-ply paper towel on top of the soil to wick off excess moisture for $10 \mathrm{~s}$, to visibly remove the 'sheen' of moisture at the surface, before loading the sample within the arena. By sampling the soil surface in the arena, and drying and weighing the samples, we established the moisture content of the mound material, which workers would encounter, to be $27 \% \pm 2 \mathrm{H}_{2} \mathrm{O}$ by weight.

\section{The experimental series}

The experiments were split into two series, S1 and S2. In the first series, designated $\mathrm{S}_{\mathrm{A}-\mathrm{I}}$, 9 runs were undertaken, where a varying temperature gradient was imposed on the soil substrate. Within any single run, we set the temperature difference of the substrate gradient, to be higher at the inlet and lower at the outlet, than the inlet airflow temperature. By noting the external air temperature, we could locate a source of heat (clothe soaked in warm water) and source of cooling (ice cubes) beneath the soil substrate, separated by a metal plate to spread the temperature towards a linear distribution. Theoretically this would produce a NEEP at some mid-point between the inlet and outlet. In this scenario, desiccated air enters the arena and encounters warm moist soil (> inlet air temperature) at its leading edge, producing vapor mass transfer from the soil to the VBL. As air moves down the arena it draws in moisture (as vapor) up to its saturated equilibrium point ( $100 \% \mathrm{RH})$. Vapor-saturated air pass over the NEEP (no vapor mass transfer between soil and air) and will condense on any surface at or below the temperature of the saturated air (i.e., the inlet air temperature).

If a vapor cycle exists around a NEEP, it should produce a region of 'stable' saturated and advected airflow, with little variation in temperature, $\mathrm{RH}$ or momentum, even though we had no way of establishing this. This stable region or 'vapor bubble' will be bounded by the freestream airflow momentum gradient above the VBL and steeper gradients of temperature, momentum and viscosity at the evaporating leading edge and condensing trailing edges of the vapor cycle.

If workers sense and act on viscosity or momentum gradients brought about through vapor mass transfers while seeking to stabilize regions which would otherwise be challenging (i.e., too dry or too wet), then we would expect to observe residency within this region and behaviors synonymous with the presence of mound material. Because of unpredictable changes to external conditions (i.e., weather conditions) affecting inlet air temperature and RH content, and predictable internal changes (such as cooling of the warm cloth and warming of the ice beneath the substrate), we would expect to see the location and extents of the NEEP and vapor cycle changing through each run. This conflicted with our hopes to observe an expanding NEEP and vapor cycle through the action of workers adding energy to the abiotic state, towards homeostatic regulation.

We produced temperature gradients of varying slope, from $15{ }^{\circ} \mathrm{C}$ difference (i.e., $\approx 7{ }^{\circ} \mathrm{C}$ either side of the NEEP and a gradient of $0.75^{\circ} \mathrm{C} \mathrm{cm}^{-1}$ ) down to $0{ }^{\circ} \mathrm{C}$ (i.e., no temperature difference above or below the NEEP). For steep gradients, a shorter vapor conveyor should form around the NEEP at some location along the baseplate, whereas shallow gradients should produce a longer vapor conveyor. We recorded substrate temperatures in-situ at the start and end of each run (Hygiplas infrared thermometer, SN:GG749, resolution $0.1{ }^{\circ} \mathrm{C}$, spot ratio $12: 1$, accuracy $\pm 2{ }^{\circ} \mathrm{C}$ ) taking readings every $25 \mathrm{~mm}$ along the substrate. Using these data and the data from the RH/T sensors, we could establish the likely location of the NEEP.

The second series, designated $\mathrm{S} 2_{\mathrm{A}-\mathrm{E}}$, explored the relationship of a discrete soil moisture transition to the emergence of the vapor conveyor, where no temperature gradient was imposed within the soil substrate. A soil moisture transition, in the presence of the diffusion limited VBL, should create a vapor conveyor similar to a soil substrate temperature gradient in series 1 . However, unlike series 1 , in series 2 experiments, the location of one end of the vapor conveyor would be fixed to the soil moisture transition point. If wet soil, above the Atterberg plastic limit, was placed towards the lead-in end (runs $\mathrm{S} 2 \mathrm{~A}_{-\mathrm{C}}$ ), then the vapor conveyor should form over this region and collapse abruptly at the transition to dry soil, which was below the Atterberg plastic limit and towards the lead-out end. Inversely, runs $\mathrm{S} 2_{\mathrm{D}-\mathrm{E}}$ had dry soil located at the lead-in and wet soil at the lead-out. If our assumptions were correct, then we would expect the vapor conveyor to begin abruptly at the moisture transition point and form over the wet soil. If worker termites exhibited sensitivity to its presence, this would address a bias towards substrate temperature, over a vapor forcing sensitivity, because the baseplate temperature was uniform. Recent studies (Green et al. 2017), report $20 \% \mathrm{H}_{2} \mathrm{O}$ by weight for 'fresh build' in Macrotermes Michaelseni mounds in the same region. The soil moisture transition was from 15 to $27 \% \mathrm{H}_{2} \mathrm{O}$ by weight over a distance of $5 \mathrm{~mm}$ within the soil substrate. 


\section{The viscous boundary layer}

As a closed system, the VBL properties in the experiments were similar to that found in a pipe. Using the experimental parameters (inlet flow velocity, arena geometry and temperature gradient) we simulated the boundary layer aerodynamics within the arena. In Fig. 3a-d, we simulated the effects of vapor transfer and temperature-driven buoyancy in the formation of the VBL, as well as symmetry breaking of the streamlines (solid black lines) of the flow. The simulation assumes a $10{ }^{\circ} \mathrm{C}$ temperature gradient along the baseplate (from 15 to $25^{\circ} \mathrm{C}$ ), which was the maximum gradient difference used in the experiments $\mathrm{S}_{\mathrm{A}-\mathrm{E}}$. In the physical experiments, the NEEP would lie midway along the baseplate temperature gradient. However, the model could not simulate the effect of a condensing condition beyond the NEEP, which would collapse the VBL towards the baseplate producing the vapor conveyor.

Figure 3 a shows the condition we observed with the twin bolii release in Fig. 2d, with no vapor transfer or temperature gradient. Air moves at a near constant velocity along the pipe or arena. Equally, in Fig. 3b, the addition of a temperature gradient does little to change the velocity profile across the pipe or flow along it. Only in Fig. 4c, with vapor mass transfer from the substrate and no temperature gradient, do we see the formation of a pronounced VBL, with distortion of the flow field producing changes to the velocity profile across the pipe. Interestingly, in Fig. 4d, we predict little change to the VBL profile, with the addition of a temperature gradient. The implication

No temperature gradient \& no vapor transfer to VBL
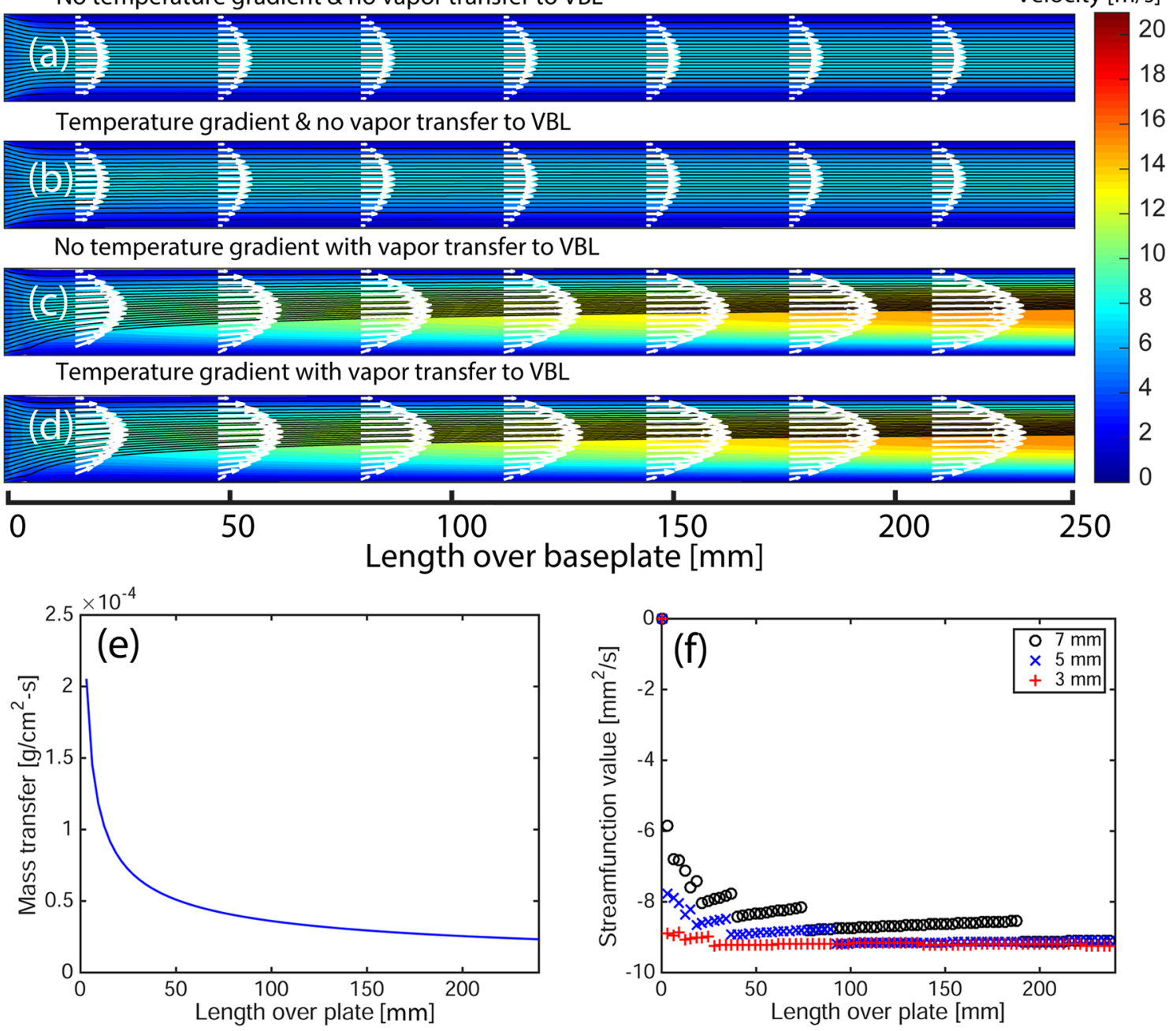

Fig. 3 a Simulated velocity profiles for the experimental equipment, where two experimental parameters $\left(10{ }^{\circ} \mathrm{C}\right.$ gradient along the baseplate and vapor transfer at the leading edge) show the effect on the formation and extent of the VBL. In $\mathbf{b}$, the temperature gradient alone has little effect on the VBL formation. In $\mathbf{c}, \mathbf{d}$, the VBL forms primar-

ily with the presence of the vapor transfer. e Theoretical mass transfer rate (assuming only vapor forcing at the leading edge) used for $\mathbf{c}, \mathbf{d .} \mathbf{f}$ The stream function values along VBL at $7 \mathrm{~mm}$ (black), $5 \mathrm{~mm}$ (blue), and $3 \mathrm{~mm}$ (red) above the surface 

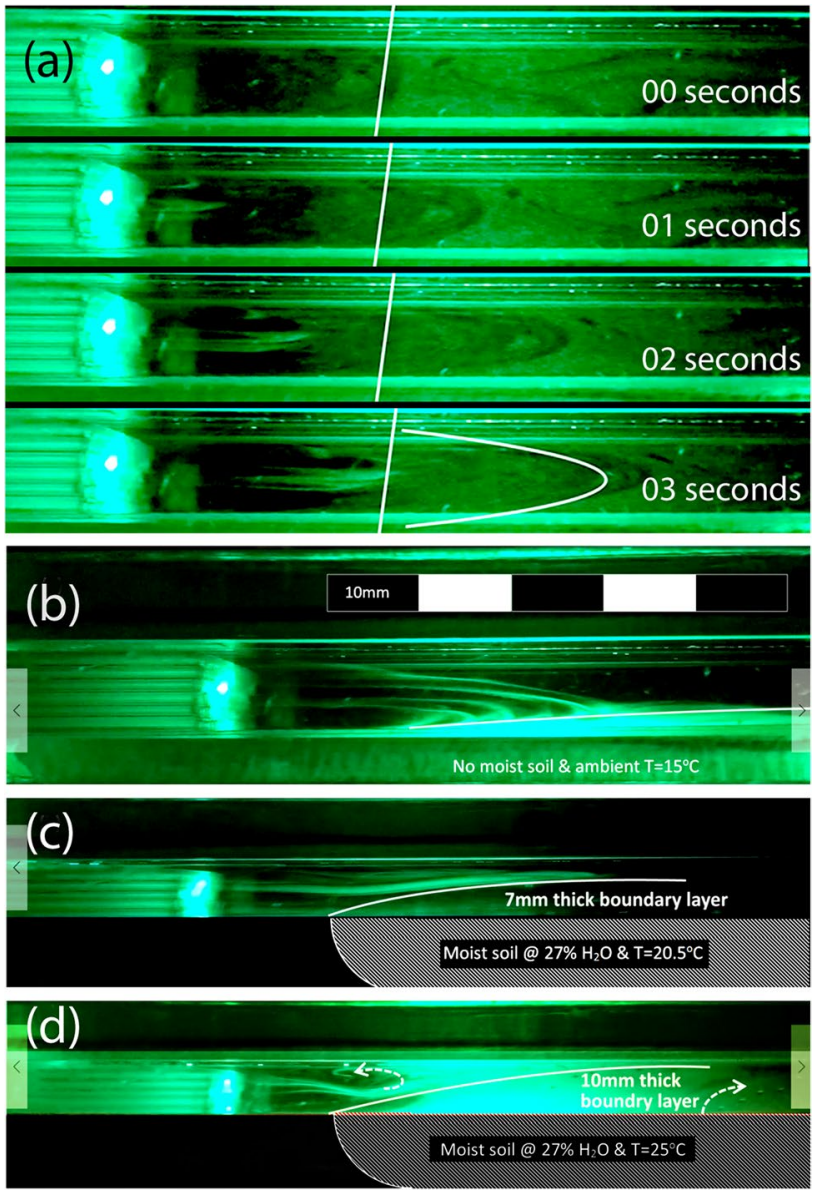

Fig. 4 a 3 s laser illuminated PEG vapor sequence showing velocity profile of experimental arena in vertical section (no moist soil present). b VBL with no moist soil or thermal forcing (arena at ambient $T \approx 15^{\circ} \mathrm{C}$ ), $\mathrm{BL}=5 \mathrm{~mm}$. c Momentum $\mathrm{BL}$, with moist soil (hatched region) and thermal $\left(\approx 20.5{ }^{0} \mathrm{C}\right) /$ vapor forcing, $\mathrm{BL}=7 \mathrm{~mm}$. $\mathbf{d} \mathrm{VBL}$ under high thermal $\left(T \approx 25{ }^{\circ} \mathrm{C}\right)$ forcing from moist soil (hatched region). VBL extends from baseplate to top plate with visible condensate on walls of arena

being that vapor transfer has a far greater effect on the shape (and height) of the VBL than temperature-induced changes in air density.

By adapting Spalding (1954), for mass transfer in laminar flow, to our experimental conditions, we determined the theoretical exchange of moisture (mass transfer) between a fully wetted soil and air at $10 \%$ relative humidity, when they are both at a temperature of $20^{\circ} \mathrm{C}$. For simplicity, our model assumed a smooth surface. In Fig. 1e, we show the expected change in moisture transfer along the length of the experimental channel. We can determine how moisture loss, or vapor mass transfer, from the substrate affects the velocity boundary layer, where moisture exchange is treated as a flow injection at the surface and the boundary condition for the boundary layer problem (Wang 2007). Where initially the rate of desorption (evaporation) to the VBL is high, this levels off as the saturation threshold of the air in the VBL is approached.

The simulation suggests that desorption to the VBL occurs rapidly, to produce NEEP conditions, even in the absence of a temperature difference between the substrate and the air stream passing over it. Where in the S1 runs we explored vapor mass transfer and the formation of the VBL through a temperature difference between the substrate and air stream above it, in the $\mathrm{S} 2$ runs we explored vapor mass transfer, where no temperature difference existed. Figure $3 \mathrm{e}$ suggests that we should still find NEEP conditions and a vapor cycle present. This also demonstrates how the alignment of the substrate temperature to airstream temperature alone will not form the NEEP, it is the rapid transfer of vapor to the VBL to its saturation point and its advection, which creates this condition.

We investigated the dynamics of the streamlines between the ground and the height of the predicted VBL. Figure $3 \mathrm{~g}$ shows the values of the stream function $\psi$ at three different heights about the surface $(7 \mathrm{~mm}, 5 \mathrm{~mm}$ and $3 \mathrm{~mm}$ ). Streamlines occur when the streamfunction $\psi$ is constant (Schlichting 1960); therefore, we expect streamlines approximately parallel to the surface for flows after they enter our experimental channel.

Streamlines are of particular interest for probing information as they represent the paths that air and other chemical molecules travel along. By probing at the same height across the channel, a termite could sense changes in air velocity and chemical properties. Interestingly, the streamlines nearer to the surface in Fig. 3g tend to be parallel. This indicates that by probing close to the surface, a termite could ensure consistency in the information it receives, while it traverses along the surface. A termite could then measure how humidity, temperature, and flow speed change along the surface as these can be integrated into the volume changes occurring within streamlines. This information could help workers reach a consensus on the ideal spots for soil excavation and deposition.

Formation and visualization of the leading edge of the VBL is shown in Fig. 4a and shows the velocity profile within the arena, over $3 \mathrm{~s}$ with no temperature forcing and no moist substrate, using dispersed (neutrally buoyant) polyethylene glycol (PEG) vapor injection and (vertical) planar laser illumination. The profiles are more elongated than Fig. 3a. In Fig. 4b-d, we first introduced PEG vapor into the VBL (as described), then neutrally buoyant streamlines over the PEG infused VBL. Figure $4 b$ shows the VBL to be around $5 \mathrm{~mm}$ thick, where it forms over an acrylic baseplate at ambient $15{ }^{\circ} \mathrm{C}$, with no soil trough. In Fig. $4 \mathrm{c}$, we introduced the moist soil trough at $20.5^{\circ} \mathrm{C}$ and Fig. $4 \mathrm{~d}$ at $25{ }^{\circ} \mathrm{C}$. There was a marked effect on VBL formation and cohesion, as simulated in Fig. 4c, d, where Fig. 4c shows the effect of a $5{ }^{\circ} \mathrm{C}$ increase to temperature at the leading edge, 
producing a thickened VBL of $7 \mathrm{~mm}$ and Fig. $4 \mathrm{~d}$, where a $10{ }^{\circ} \mathrm{C}$ (above ambient) increase at the leading edge produced disruption to the VBL. In Fig. 4d, we see symmetry breaking of streamlines just ahead of the VBL, as well as disruption within the VBL (dashed arrows). This is the threshold over which temperature-induced convection based mixing occurs in the VBL.

\section{Mapping activities and analysis}

Each run in $\mathrm{S} 1_{\mathrm{A}-\mathrm{I}}$ and $\mathrm{S} 2_{\mathrm{A}-\mathrm{E}}$, lasted $60 \min (t=1$ to $t=60)$. Activities within the arena were recorded continuously by a GoPro video camera mounted above the arena. For each run we marked off to a $12 \times 60$ excel grid, the location of workers along the arena and coded that mark based on their activity in that location. The 12 cells in each column represented 12 incremental locations (of $25 \mathrm{~mm}$ each) covering the length of the arena, beginning at the inlet (called 'lead-in') to the outlet (lead-out). The 60 rows represented $60 \times 1 \mathrm{~min}$ increments, where the video was paused and worker residency/ activity count took place. At $t=1$ we coded the location of an activity to column 1 as either a clustering $=1$, deposition $=2$ or excavation $=3$, and so on to column $t=60$. We did not code for workers moving between locations or between any of the three activity categories.

The observation category called 'clustering' describes how workers sometimes cluster in groups at certain locations, where they may or may not later engage with excavation or deposition activities. The term 'clustering' has been called 'aggregation' (Dambach and Goehhlen 1999) in studies of cockroach sensitivity to humidity, but becomes confusing when describing termites that aggregate materials.

Coding cells by 'activity' allowed us to apply conditional arguments and color formats for analysis. By adding two additional columns, one before $t=1$ and one after $t=60$, we could input the substrate temperature gradient at $t=0$ and $t=61$. These substrate temperature data were interpolated for all columns $t=1$ to $t=60$ in the 'activity grid', producing an approximate substrate temperature for each cell in the grid, where a coded activity took place. For clarity our interpolated substrate temperatures assumed a linear temperature gradient between $t=1-t=60$, which we could not know.

As with the substrate temperatures, the VBL temperature data (taken from the humidity sensor logs) were mapped to all cells in the activity grid. Conditional formatting was applied to indicate cells, where the substrate temperature matched the VBL air temperature $\left( \pm 1{ }^{\circ} \mathrm{C}\right.$ either side of the VBL temperature) as the likely location of the NEEP. Using $\pm 1{ }^{\circ} \mathrm{C}$ was a choice based partly on the accuracy of measurements using the infrared thermometer, and because this range corresponded to a single cell in column $t=0$, where steeper temperature gradients were applied. [Details can be found in supplementary data: SD1].
By introducing the location of cells, where activities occurred (and the corresponding substrate temperature) we could map these to cells that converged on the VBL air temperature. With these data we could calculate the percentage of cells, where activities occurred that fell within the bounds of the NEEP. Because of the tight coupling of parameters (soil moisture, surface roughness, soil matric potential, topology modification and airflow) and the inevitable variation in external air pressure and temperature conditions, it was impossible to fix the location of the NEEP to a single location along the substrate gradient, prior to each run. Instead we exposed workers to randomly varying temperature and moisture gradients, logged the airflow and substrate parameters for each run and then ranked these by gradient for the analysis.

A final set of observations were the visible extents of the vapor cycle at the soil/air interface through each run. We had two methods for establishing this. The first has been described in Fig. 2g, using white light reflectance. The second was to use PEG vapor infusion to the VBL and planar laser illumination to see, where the PEG vapor condensed to the substrate. These were also be mapped to the activity grid to see how these aligned to the NEEP.

\section{Results}

Figure 5 shows activity pictograms for all 14 runs and their $12 \times 60$ cell 'activity grids'. The first series, $\mathrm{S} 1_{\mathrm{A}-\mathrm{I}}$, are ranked by the temperature gradient $\left(0.89-0.11{ }^{\circ} \mathrm{C} \mathrm{cm}^{-1}\right)$ along the baseplate. Coded activities have been color rendered (clustering $=$ magenta, deposition $=$ green, excavation $=$ blue), as have the soil substrate temperature gradients (from $12{ }^{\circ} \mathrm{C}=$ yellow to $30{ }^{\circ} \mathrm{C}=$ red) to show the interpolated profiles at $t=1$ and $t=60$ (ordinate) for each run. In Fig. 5, blue excavation events are identified as both excavation and deposition events, which is discussed later. In series $\mathrm{S} 1_{\mathrm{A}-\mathrm{I}}$ the location of the NEEP is indicated as existing between the two vertical dashed lines, where the VBL temperature $\left( \pm 1^{\circ} \mathrm{C}\right)$, matches the substrate temperature for each cell. The calculation of this region is shown in the supplementary data (SD1: Table 2). In addition, in Fig. 5, the region between the gray triangles ' $><$ ' represents the extent of the visible vapor conveyor within the VBL, established using PEG vapor laser illumination and white light reflectance off the condensate on the substrate.

In runs with steeper gradients, $\mathrm{S} 1_{\mathrm{A}-\mathrm{F}}$, expansion of the vapor conveyor was biased towards the leading edge, most likely because of faster heat dissipation through the run, from the warm soil substrate (as opposed to heat gain at the cold end). Both the calculated NEEP extents and the visible extents of the vapor conveyor expanded in line with the number of cells, where activities took. In $S 1_{G}$ we could 


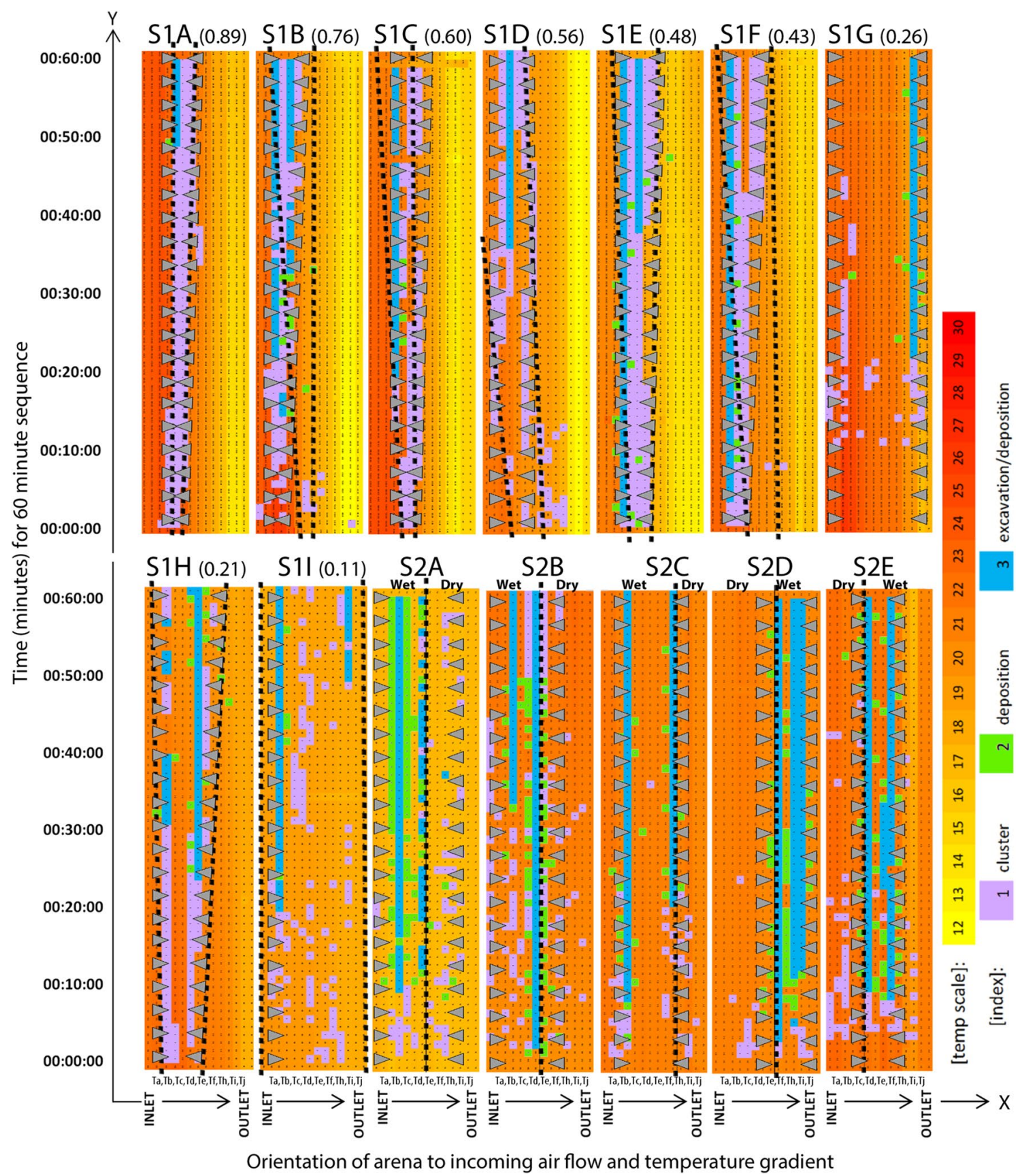

Fig. 5 Color rendering of the 14 grid arrays used to encode category, duration and location of activities for all runs (abscissa $=$ direction of airflow and coding locations along arena Ta-j). Coded activities (clustering, deposition, excavation) were mapped to soil temperature contours $\left(12{ }^{\circ} \mathrm{C}=\right.$ yellow to $30^{\circ} \mathrm{C}=$ red) for each $60 \mathrm{~min}$ run (ordinate).
Runs $\mathrm{S} 1_{\mathrm{A}-\mathrm{I}}$, sought to correlate the NEEP (area between vertical dashed black lines), and visible extent of vapor conveyor from videos (area between the gray triangles). Runs S2 A-E explore the emergence of the vapor conveyor, where no temperature gradient exists, only a sharp soil moisture transition (vertical dashed line) not calculate the NEEP extents due to RH/T sensor failure. $S 1_{D}$ shows skewing suggesting the calculated NEEP is moving outside the bounds of the baseplate temperature gradient, possibly from changes in external pressure and temperature conditions. In $S 1_{I}$ the bounds of the NEEP may have extended beyond the arena due to the shallow gradient, accounting for the broad range of the activities recorded throughout the arena.

In the second series, $\mathrm{S} 2_{\mathrm{A}-\mathrm{E}}$, the location of a discrete soil moisture transition is indicated as a single vertical dashed line. The NEEP could not be established to any degree of accuracy, because the vapor conveyor was being forced into 
existence by the soil substrate condition. The visible extents of the vapor conveyor were again recorded as the region between the gray triangles ' $><$ '. In four of the five runs, the soil moisture transition did form either the beginning or end of the vapor conveyor. Notably in run $\mathrm{S} 2{ }_{\mathrm{A}}$, the visualized conveyor extended beyond the moisture transition point, as did the extent of activities.

In general, all runs began with workers clustering (magenta) near or at locations which would become sites of activity, as either excavation (blue) or deposition (green). Activities were not fixed to any single location along the soil trough, for example, where workers tend to be drawn to 'edges' (Green et al. 2017), which in this case would be the point, where the soil trough transitions to the acrylic baseplate, at its leading or trailing edge. In all S1 runs, where a temperature gradient existed, activities began and remained within the visible bounds of the vapor conveyor. In $\mathrm{S} 1_{\mathrm{A}-\mathrm{I}}$, except $\mathrm{S} 1_{\mathrm{B}}$ and $\mathrm{S} 1_{\mathrm{F}}$, activities began within $1{ }^{\circ} \mathrm{C}$ either side of the NEEP, with both vapor conveyor and the extent of activities expanding through the run. In $\mathrm{S} 2_{\mathrm{A}-\mathrm{E}}$, the imposed soil moisture transition defined both the limit to the vapor conveyor and primary sites of excavation activity. Notably, the extents of the vapor conveyor did not change compared to $\mathrm{S} 1_{\mathrm{A}-\mathrm{I}}$.

Figure 6a [i-vi] shows 6 captured frames covering $25 \mathrm{~s}$ of video from the end of run $\mathrm{S}_{\mathrm{E}}$. Figure 6a [i] shows PEG streamlines (injected at $>5 \mathrm{~mm} \mathrm{~s}^{-1}$ ) emerging from the lowest layer of capillary tubes at the inlet. The laser plane is set $\approx 2-3 \mathrm{~mm}$ above the baseplate. Workers are illuminated and streamlines around them are visible, within the VBL. In Fig. 6a [ii], streamlines encounter workers actively excavating at the leading edge (circled) of the vapor conveyor (indicated), where streamline velocity changed from $5 \mathrm{~mm} \mathrm{~s}^{-1}$ to $3.6 \mathrm{~mm} \mathrm{~s}^{-1}$. On sensing streamlines, 3 workers move upstream. Streamline flow around workers shows a boundary layer forming around the abdomen (see discussion). In Fig. 6a [iii], streamlines persist as they encounter workers at the trailing edge, but are forming vortices and eddy characteristics. PEG vapor now makes up part of the vapor-saturated air in the VBL. Streamlines track along the vapor conveyor in Fig. 6a [iv-v], becoming diffuse and then condense on the cool soil (see supplementary video SV1).

In Fig. 6a [vi], workers (indicated by red '^') remain clustered at the trailing edge of the vapor conveyor. A single worker (indicated blue ' $v$ ') moves downstream of the cluster, away from the vapor conveyor (see discussion and supplementary video SV2). In Fig. 6b, a brief but intense pulse of PEG vapor injection forms a diffuse cloud within the entire arena (i.e., no streamlines). The extents of the illumination cone of the planar laser (green arrows) show the cloud condensing to the substrate the right of the clustered workers. Again, individual workers leave the conveyor and move downstream. This behavior was common through all runs and occurred in the absence of PEG vapor. Because there workers were mobile $\left(\approx 5 \mathrm{~mm} \mathrm{~s}^{-1}\right)$ we excluded them from the coding.

Figure $6 \mathrm{c}$ (i) shows the typical deposition around a site of excavation. Figure $6 \mathrm{c}$ (ii) plots the spatial distribution (mm) of every deposition event adjacent to and within $\approx 25 \mathrm{~mm}$ from a single excavation site (indicated by red circle) from $\mathrm{S} 2{ }_{\mathrm{D}}$. Deposition is bounded by the walls of the arena, top and bottom. Figure $6 \mathrm{c}$ (iii) shows the deposition distribution along the abscissa from the region of interest in Fig. 6c (ii) (blue dashed rectangle), showing slight skewing to one side of the arena. Where we coded sites of excavation (blue) in Fig. 5, there was always deposition adjacent to that location and these were included in the 'excavation' activity count.

We coded sites of deposition (green) only where a deposition event lay $\geq 25 \mathrm{~mm}$ away from the normal deposition distribution around an excavation site. Across S1 and S2 runs, there were 264 deposition events $\geq 25 \mathrm{~mm}$ from an excavation site, compared to 25 deposition events at $\geq 50 \mathrm{~mm}$ from a site of excavation. Only in $S 1_{D}$, were there no deposition events $\geq 25 \mathrm{~mm}$ away from an excavation site. Deposition sites persisted temporally in a single location along the arena. In $\mathrm{S} 2_{\mathrm{A}}, \mathrm{S} 1_{\mathrm{B}}$, and $\mathrm{S} 1_{\mathrm{D}}$ deposition events occurred contiguously (across $60 \mathrm{~s}$ increments), whereas the remaining run saw sporadic deposition at a single location. The frequency between deposition actions being on average $5 \min ( \pm 5)$.

Table $1 \mathrm{C} 1$ shows series $\mathrm{S} 1$ runs, ranked by imposed temperature gradient (steepest to shallowest), where C2-C4 show the minimum and maximum temperatures recorded along the soil substrate. $\mathrm{C} 5$ shows that the randomized selection of each run's substrate temperature gradients fell close to a linear distribution $\left(0.0928 x_{\text {gradient }}+0.9394\right.$, $R^{2}=0.98$ ) covering the range of gradients from $0.89^{\circ} \mathrm{C} \mathrm{cm}^{-1}$ to $0.11{ }^{\circ} \mathrm{C} \mathrm{cm}^{-1}$, see supplementary data (SD1: Graph1). C6 lists the number of cells, where activities occurred for each run. In supplementary data (SD1: Graph2 and Graph5) we show an approximate logarithmic relationship between cells with activities and decreasing substrate gradient $(Y=$ $\left.-3.06 \ln \left(x_{\text {gradient }}\right)+3.75, R^{2}=0.739\right)$. C5 and C6 were negatively correlated $(-0.78$, P.E. $=0.88)$.

C7 lists the average substrate temperature, where activities occurred and C8 lists the average inlet air temperature through each run, see supplementary data (SD1: Graph 6). In all runs, except $S 1_{\mathrm{G}}$, where sensors failed, the average substrate temperature, where activities were coded was $20.87^{\circ} \mathrm{C}$, and this fell within $0.2{ }^{\circ} \mathrm{C}$ (av. $97.9 \%$ ) of the average inlet air temperature of $20.66^{\circ} \mathrm{C}$ in $\mathrm{C} 8$. Pearson correlation between these factors was 0.68 , with only run $S 1_{B}$ being negatively correlated and $>2{ }^{\circ} \mathrm{C}$ difference. We estimate a $0.5{ }^{\circ} \mathrm{C}$ error on the process of recording temperature (i.e., when the arena was opened to take the infrared measurements at the start and end of each run). 


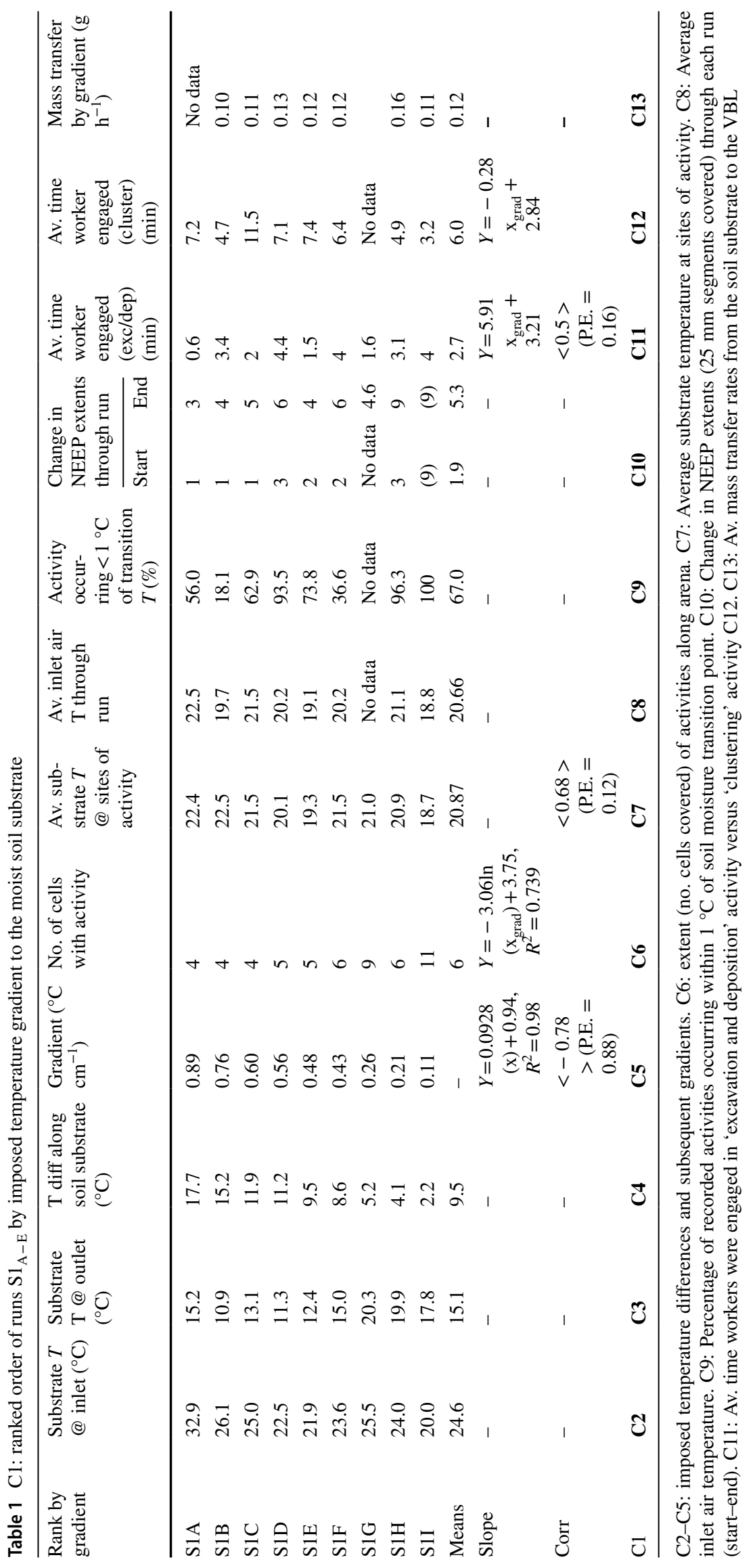




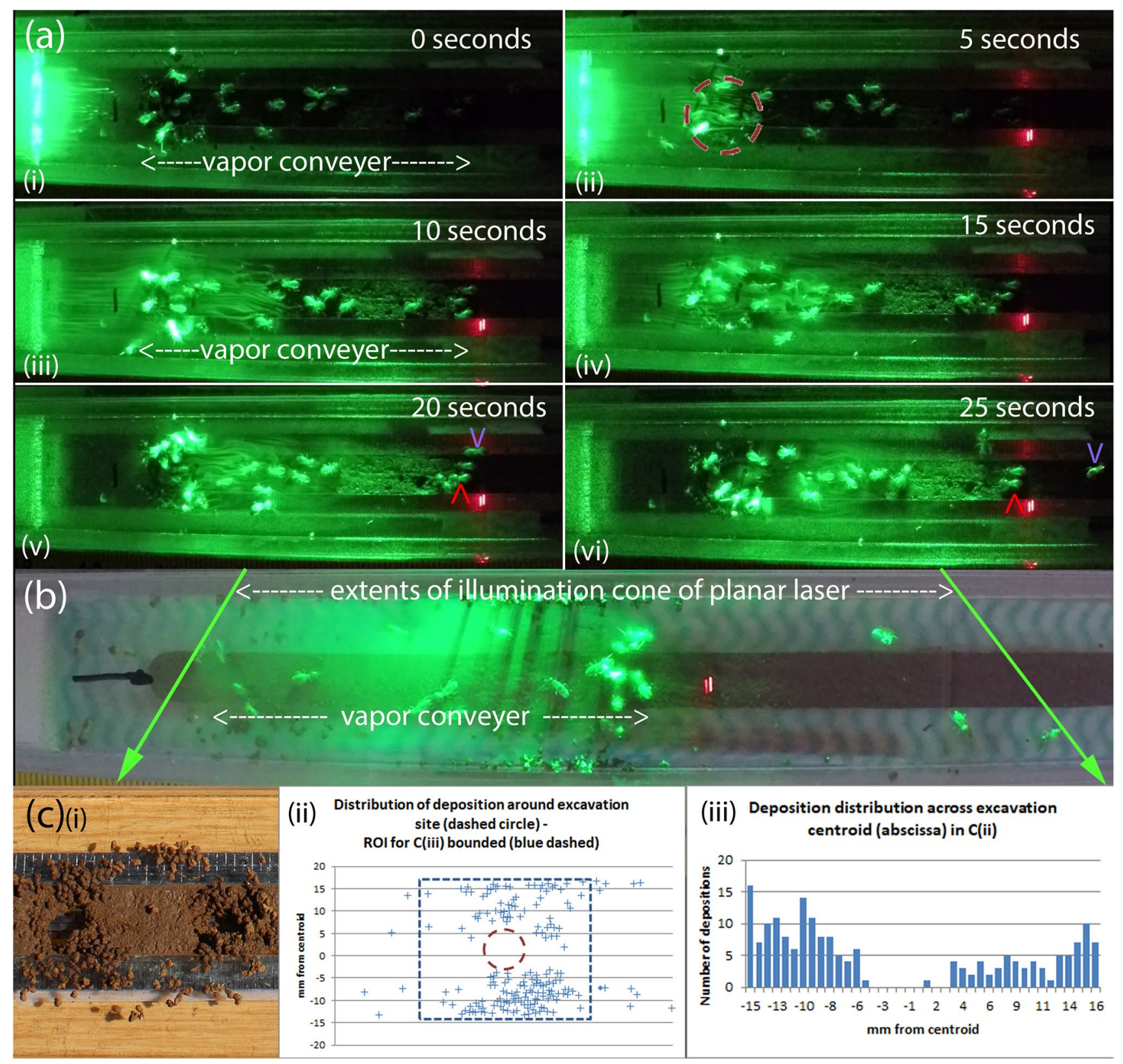

Fig. 6 a [i-vi] from run $\mathrm{S}_{\mathrm{E}}$ showing $25 \mathrm{~s}$ sequence of laser illuminated PEG visualization of streamline flow within the VBL. b Laser illuminated PEG vapor showing the extent of vapor conveyor within the VBL. PEG vapor is entrained within the vapor conveyor and is

C9 lists the percentage of cells, where activities were coded, whose substrate temperatures fell $1{ }^{\circ} \mathrm{C}$ either side of the NEEP (as dashed vertical lines in Fig. 5, $\mathrm{S}_{\mathrm{A}-\mathrm{I}}$ ), where $100 \%$ would indicate that all cells with activity occurred within $1{ }^{\circ} \mathrm{C}$ either side of the NEEP. In 6 of 8 runs, where data was available $\left(\mathrm{S}_{\mathrm{G}}\right.$ had no inlet $\mathrm{T}$ data), $>50 \%$ of cells fell within $1{ }^{\circ} \mathrm{C}$ (av. 67\%). In Fig. 5, $\mathrm{S} 1_{\mathrm{B}}$ and $\mathrm{S} 1_{\mathrm{F}}$ had NEEP extents away from cells marked by activity, at the start of condensing (to left of red 'II' mark) to the soil substrate, just ahead of the clustered workers. c (i-iii) Typical distribution of deposition events around a site of excavation

the run, but both converged to the sites of activity through the run.

C10 quantifies the expanding zone of vapor conveyance around the NEEP, as the number of cells covered along the arena, at the start and then end of each run, see supplementary data (SD1: Table 2). These increased from an average of 1.9-5.3 cells covered (excluding $\mathrm{S}_{1}$, where the extents covered the whole arena throughout the run). 
$\mathrm{C} 11$ and $\mathrm{C} 12$ list 'worker productivity', as the number of cells, where activities occurred ( $t=1$ to $t=60$ ), representing the time any single activity lasted (minutes), as a proportion of the number of workers in the run, see supplementary data (SD1: Graph 3). In C11, excavation/deposition events were combined as deposition events accounted for $<1 \%$ of excavation events and in $>90 \%$ of cases, these were an extension of the excavation site. The mean of C11 (2.7 activity count/ worker) and $\mathrm{C} 12$ (6.0 activity count/worker), indicate that excavation/deposition events accounted for $45 \%$ of all events versus 55\% for clustering events, with the $\mathrm{C} 11$ and $\mathrm{C} 12$ being weakly correlated (0.5). Where excavation/deposition events remained fairly constant $\left(\mathrm{y}=-0.2893 \mathrm{x}_{\text {gradient }}+2.8445, R^{2}=\right.$ $0.0029)$ as gradients increased, clustering events increased $\left(y=5.9164 \mathrm{x}_{\text {gradient }}+3.2107, R^{2}=0.2859\right)$, peaking at around $0.6^{\circ} \mathrm{C} \mathrm{cm}^{-1}$.

$\mathrm{C} 13$ lists net mass transfer $\left(\mathrm{g} \mathrm{h}^{-1}\right.$ ) (outlet \% RH inlet $\%$ RH data) of soil moisture to the VBL through each run (av. $0.12 \mathrm{~g} \mathrm{~h}^{-1)}$, see supplementary data (SD1: Table 3). Averaging the mass transfer rates across all runs at $t=0$, $t=10, \ldots t=60$, there was an increase in mass transfer $\left(y=0.028 \ln \left(x_{t 0 \ldots t 60}\right)+0.0883, R^{2}=0.93\right)$ from $0.08 \mathrm{~g} \mathrm{~h}^{-1}$ at the start and $0.13 \mathrm{~g} \mathrm{~h}^{-1}\left( \pm 0.05 \mathrm{~g} \mathrm{~h}^{-1}\right)$ at the end of the run. Under perfect conditions, the vapor conveyor would expand and collapse within the VBL with no change to mass transfer, between the inlet and outlet RH sensor. In reality, the diffusion dominated VBL is not a closed system and there will always be some loss, as mass transfer to the free-flow stream, above the VBL.

In Fig. 3a-d, we presented the simulated aerodynamics within the arena. The model that we used for the vapor forcing (Spalding, 1954) resulted in an exponential-like decay in moisture loss, as shown in Fig. 3e. We found that the simplified model captured the exchange of moisture between the water containing surface and desiccated air. Specifically, the model predicted a transfer of moisture of $\approx 0.15 \mathrm{~g} \mathrm{~h}^{-1}$, which approximated the average physical measurement of $0.11 \mathrm{~g} \mathrm{~h}^{-1}$ (range from 0.08 to $0.13 \mathrm{~g} \mathrm{~h}^{-1}$ ), established during the initial setup running desiccated air over the moist soil surface.

\section{Discussion}

In all runs, 'clustering' events (magenta in Fig. 5) preceded sites of excavation activity. However, there was variability in the time into the run, when excavation began, see supplementary data (SD1: Graph 7) and only in 2 runs did excavation begin immediately $\left(\mathrm{S} 1_{\mathrm{E}} 0.48{ }^{\circ} \mathrm{C} \mathrm{cm}^{-1}\right.$ and $\mathrm{S} 1_{\mathrm{F}} 0.56{ }^{\circ} \mathrm{C}$ $\mathrm{cm}^{-1}$ ). We could not correlate the time to commencement of excavation, to any specific soil moisture content, nor whether an optimum soil moisture gradient initiates excavation and further recruitment.
In the $\mathrm{S} 1_{\mathrm{A}-\mathrm{I}}$ study group, we were moving moisture from a warmer region to a cooler region, because, logically, a temperature-driven vapor conveyor can only occur in one direction. This seems counterintuitive from what we see in termite mounds, where workers are excavating inside the mound (where it is cooler) to bring moisture and soil to dryer (warmer) regions at the outside and this was partly the motivation for the $\mathrm{S} 2_{\mathrm{A}-\mathrm{C}}$ series.

Dry soil adsorbs (condenses) vapor strongly, acting like a cool surface, whereas wet soil desorbs moisture strongly, acting like a warm surface. In the vapor mass transfer simulation in Fig. 3 e, we showed how vapor mass transfer occurs between the substrate and the VBL, where a difference in the vapor carrying capacity (at low $\mathrm{RH}$ ) exists in the VBL and no temperature difference exists between the two. The role of vapor mass transfer accounts for much of the shape and thickness of the VBL. There is still a temperature component, but it can be greatly reduced when considering wet versus dry regions and this, we believe, is what occurs in the mound. Dissect a mound, as in Fig. 7a, and a moisture phase transition zone is seen at the dashed white line, between the moist domain, inside the mound, and the vapor domain leading from the transition to the outside. It is here that construction and modification begin, gradually extending construction within the stability of a saturated VBL.

Linking this to the experiment, this would be equivalent to having wet soil at the lead-in and dry soil at the lead-out, with a soil moisture transition zone (as opposed to a temperature transition zone) midway between them. The second study group recreated this condition in $\mathrm{S} 2_{\mathrm{A}-\mathrm{C}}$, with $\mathrm{S} 2_{\mathrm{D}-\mathrm{B}}$ the reverse for comparison. Workers were immediately active at the soil moisture transition. In these runs we began to see fewer clustering events and more deposition events around excavation sites, with workers excavating and transporting soil pellets (moisture pellets) to the leading edge of the substrate, even where we reversed the moisture gradient in runs $\mathrm{S} 2_{\mathrm{D}-\mathrm{E}}$. In effect workers were moving moisture to the edge of the dry zone, theoretically and gradually thickening the VBL and expanding the vapor conveyor.

Insects sustain and exploit a VBL around them by constraining air movement with arrays of setae which improve viscous coupling between the mechano-sensing fibers on the body. Viscous coupling helps amplify the signals they obtain for airflow with sensing fiber arrays, whereby the hairs interact with each other through viscous interactions with the surrounding flow (Casas and Dangles 2010; Steinmann et al. 2006; Barth and Dechant 2003; Tautz 1989; Barth 2014).

Figure $7 \mathrm{~b}$ shows greater detail from the streamline study in Fig. 6a. A worker is highlighted (red circle) and detail of streamline flow around the worker is visible. Termite morphology, tied to the viscosity of the air in the VBL, conserves laminar flow around the body contours, where potentially setae sustain a boundary layer at $\approx 600$ microns. As the 
Fig. 7 a Sections through two mounds showing the moisture transition zone. b Termite morphology may reflect skin drag convergence. Streamlines passing around a worker show a 600 micron boundary layer. c Workers frequently 'meander' away from the imposed vapor conveyor, commensurate with the airflow. Paths were mapped and initially follow the bounds of the soil trough then deviate along the arena. d Illuminated PEG vapor shows worker 'trapped' within a vapor halo through antennated feedback to a varying vapor density
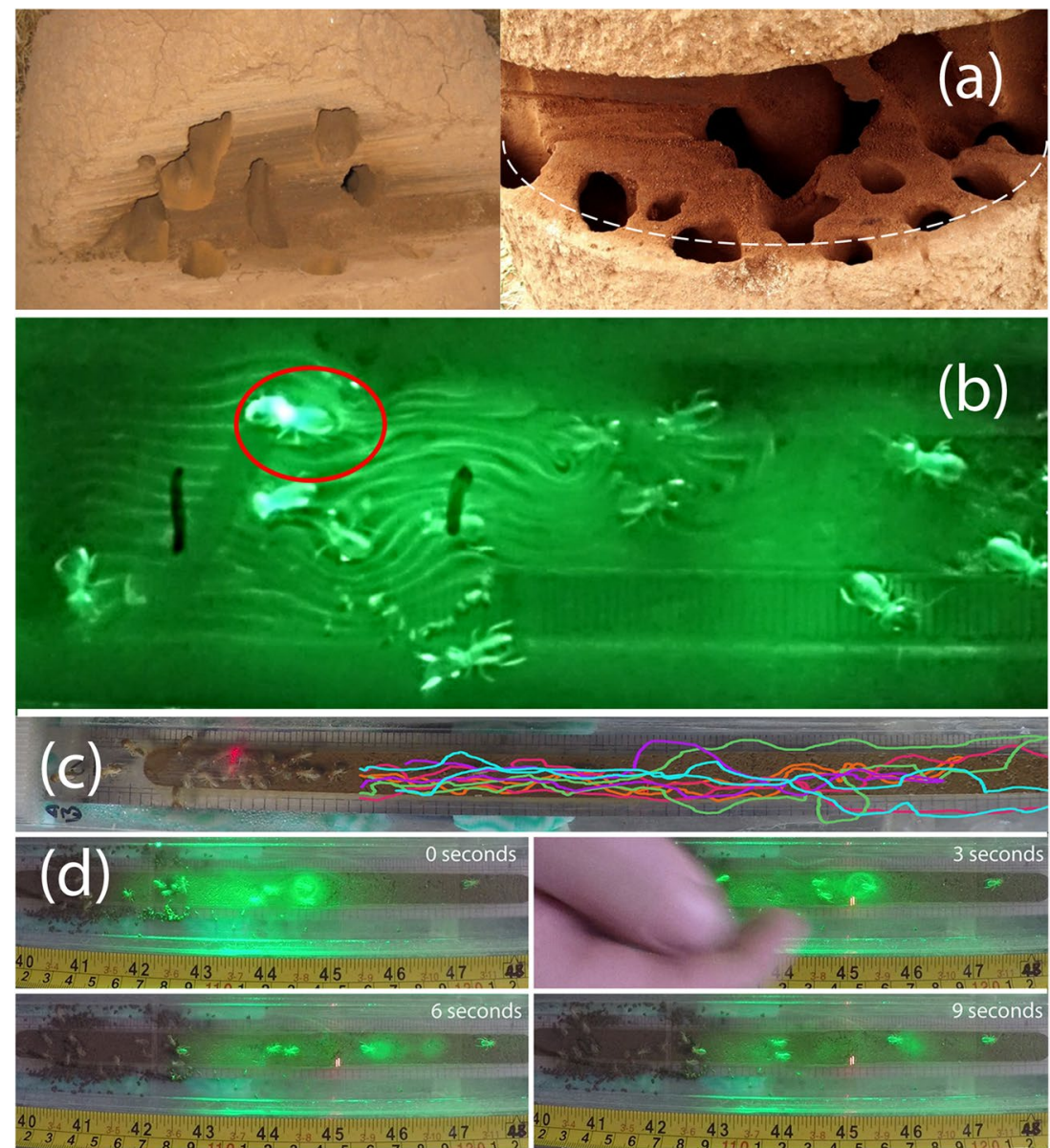

worker encountered the streamlines it initiated a 'sneeze' response (discussed previously) which had a marked effect on the streamlines passing around it, producing a coherent and single eddy (or void in the streamlines) which remained preserved within the VBL and could be sensed by other workers downstream. The potential to impart information to other workers, by the actions of those upstream may be something unique to the viscous conditions found at this scale.

In Fig. 6a [vi], a blue ' $v$ ' indicated a worker seen casting (i.e., follow a meandering but vectored path) away from the vapor conveyor. 'Casting', as defined by (Lee et al. 2008) by individuals (not groups), was a common occurrence and seemed at odds with the general behavior of clustering and excavation within the vapor conveyor. Notably, workers seen leaving the bounds of the vapor conveyor, would move at the same rate as the air stream $\left(5 \mathrm{~mm} \mathrm{~s}^{-1}\right)$ while darting from side to side. When mapped in Fig. 7c, workers were seen to cast down the arena and then return to the vapor conveyor, frequently via a different path.

This runs counter to standard description for pheromone trail following. Occasionally a worker would head off down the arena and meet a worker coming back. Both would stop and turn around, the first heading back to the vapor conveyor, the other meandering along a path that presumably the first would have followed. Figure 7d (see supplementary video SV2) shows, where PEG vapor illumination was able to visualize a possible cause. The viscosity of the medium to the worker allows for an antennal interaction, where a specific movement of the antennae creates a single eddy vortex as a ring or 'halo' of dense vapor, which persists. As the halo moves down the arena the initiating worker will follow it. This appears to override any other sensory input from the vapor conveyor. In the case of the 'hand-off' to another worker, the meeting appears to disrupt the first worker's 'attention', enough that it retraces a route back to the vapor conveyor, leaving the second worker 'consumed' by a moving vapor halo above its head.

From an antennated sensory perspective, workers interact with a broad range of sensory cues from the environment and they will select tasks which may seem to conflict. In this study, with unique conditions (compared to those found in the mound), we saw a favored residency within a vapor cycle being overridden by eddy vortices forming around them, which they follow towards potentially unfavorable conditions elsewhere. The halo would have little or no momentum 
difference to surrounding air, only a vapor density difference, which they appear to sense and become trapped within, causing them to venture beyond the vapor conveyor, onto the cooler and/or condensing end of the soil substrate.

Over evolutionary timescales, physiological adaptation to the VBL may have 'converged' through the process of mound building. Through construction, workers may be pumping vapor to the VBL to expand it to a thickness coincident to the size of the termites. They work within the VBL, frequently antennating its upper bounds, which the streamfunction simulation in Fig. $3 \mathrm{f}$ showed to be optimal at $3 \mathrm{~mm}$, above a uniformly smooth and porous substrate. In our experiments, termites were observed to probe the surrounding airflow between the surface and a height of $\approx 7 \mathrm{~mm}$. The clay to aggregate ratios in soil substrates in this region $(\approx 1: 3)$ and soil roughness, will increase vapor mass transfer to the VBL markedly. We could readily expect the actual stream function to be effective to $5-7 \mathrm{~mm}$ to coincide with the height of the major workers in the study group.

At the scale of termites, a diffusion limited vapor conveyor extends a 'protective shell' of stability, in which the humidity is high (i.e., reduced desiccation), and where soil moisture remains at its optimum 'buildability'. This may overcome a classic trade-off encountered by insects, particularly termites, at this scale. How to push construction forward (as the colony grows) into desiccating and potentially lethal transient environments while conserving a stable balance of moisture in the organism.

This paper explored the motivation of worker termites, when confronted with mound material and moisture gradients within their immediate environment. We cannot say how moisture sensitivity and regulation sit within the broader discussion on stigmergy, where 'evaporation' could be considered alongside pheromone decay. The study suggests that it probably is not, the vapor cycle described will emerge spontaneously wherever its interrelated parameters coincide. This attracts workers, that become active within it and they potentially exploit it to their own ends. Within a stable bubble of saturated vapor, trail pheromone decay will exist, possibly even a secondary build pheromone, within the overarching presence of a vapor cycle.

\section{Conclusion}

We show how worker termites sense and interact with soil moisture and water vapor within their immediate environment and describe the nature of vapor mass transfer within the viscous boundary layer (VBL), which forms over all surfaces, and its relationship to worker termites at their scale. The experiments recreated an artificial VBL in which it was theorized that the phenomenon of a 'vapor conveyor' would emerge, where mass transfer of vapor to and from the VBL occurred as a cycle of evaporation and condensation from a moist substrate, because, at this scale, the VBL approaches a diffusion limited condition.

A vapor conveyor forms around a region, where the moist substrate is neither in an evaporative or condensing state, which we term a neutral evaporative equilibrium point (NEEP), because in this location the substrate temperature matches the air temperature in the VBL, at $100 \%$ vapor saturation. Because air in the $\mathrm{VBL}$ is free to adsorb vapor up to its saturation point (100\% RH) ahead of the NEEP, vapor and air move advectively along the VBL beyond the NEEP, where vapor is free to condense back to the substrate, if either (i) the substrate temperature is cooler than the VBL or (ii) the substrate is dryer than the soil moisture level at the NEEP.

Cohorts of Macrotermes michaelseni workers were exposed to both conditions and we recorded 3 classes of activity (excavation, deposition and clustering). Activities were mapped to the substrate condition and the extents of the vapor conveyor, forming around the NEEP, were established (i) by physical observation of laser illuminated polyethylene glycol (PEG) vapor release into the VBL and (ii) by numerical correlation between the VBL temperature and its equivalent location along the substrate temperature gradient.

We found negative correlation between the extents of the vapor conveyor within the VBL and the steepness of the substrate temperature gradient. Within the runs, we found the extents of the NEEP expanding either as a response to changing substrate gradient and the activity of workers within the vapor conveyor.

Our findings suggest that the emergence of the vapor cycle, around a single point of neutral evaporative equilibrium (as we created), governed the location of a variety of behaviors associated with the maintenance of termite nests. Attracting workers to labor sites is required to organize both nest expansion and the excavation of soil that results in remodeling of the internal tunnels of the mound. Future research should focus on soil moisture profiles within the mound and other types of stimuli that work in concert with moisture to initiate worker behavior.

Acknowledgements The research was funded by the Human Frontiers Science Program (RGP0066/2012, "From swarm intelligence to living buildings, novel concepts of managing internal climates"). The authors thank the Cheetah Conservation Fund in Otjiwarongo, Namibia and Dr Eugene Marais (National Museum of Namibia) for their invaluable and continued support.

Open Access This article is distributed under the terms of the Creative Commons Attribution 4.0 International License (http://creativeco mmons.org/licenses/by/4.0/), which permits unrestricted use, distribution, and reproduction in any medium, provided you give appropriate credit to the original author(s) and the source, provide a link to the Creative Commons license, and indicate if changes were made. 


\section{References}

Alvenas G, Jansson P (1997) Model for evaporation, moisture and temperature of bare soil: calibration and sensitivity analysis. Agric For Meteorol 88(1-4):47-56

Amador GJ, Durand F, Mao W, Pusulri S, Takahashi H, Nguyen V-T et al (2015) Insects have hairy eyes that reduce particle deposition. Eur Phys J Spec Top 224(17-18):3361-3377

Bardunias PM, Su N-Y (2010) Queue Size determines the width of tunnels in the Formosan Subterranean Termite (Isoptera: Rhinotermitidae). J Insect Behav 23(3):189-204

Barth FG (2014) The slightest whiff of air: airflow sensing in arthropods. In: Bleckmann H, Mogdans J, Coombs S (eds) Flow sensing in air and water. Springer, Berlin, pp 169-196

Barth FG, Dechant H-E (2003) ArthropodcCuticular hairs: tactile sensors and the refinement of stimulus transformation. In: Secomb TW (ed) Sensors and sensing in biology and engineering. Springer, New York, pp 159-171

Blasius H (1908) Grenzschichten in Flüssigkeiten mit kleiner Reibung. Zeitschrift fuer Mathematik Physik 56(1):1-37

Bruinsma OH, Wilde JD, Leuthold RH (1979) An analysis of building behaviour of the termite macrotermes subhyalinus (Rambur). Landbouwhogeschool, Wageningen

Casas J, Dangles O (2010) Physical ecology of fluid flow sensing in arthropods. Annu Rev Entomol 55:505-520

Cooter RJ, Baker PS (1977) Weis-Fogh clap and fling mechanism in Locusta. Nature 269:53-54

Dambach M, Goehhlen B (1999) Aggregation density and longevity correlate with humidity in first-instar nymphs of the cockroach (Blattella germanica L., Dictyoptera). J Insect Physiol 45:423-429

Fouquet D, Costa-Leonardo A, Fournier R, Blanco A, Jost C (2014) Coordination of construction behavior in the termite Procornitermes araujoi: structure is a stronger stimulus than volatile marking. Insect Soc 61:253-264

Green B, Bardunias P, Turner JS, Nagpal R, Werfel J (2017) Excavation and aggregation as organizing factors in de novo construction by mound building termites. Proc R Soc B 284:20162730

Heylighen F (2016) Stigmergy as a universal coordination mechanism I: definition and components. Cog Sys Res 38:4-13

Jouquet P, Lepage M, Velde B (2002) Termite soil preferences and particle selections: strategies related to ecological requirements. Insest Soc 49(1):1-7

Kandasami RK, Borges RM, Murthy TG (2016) Effect of biocementation on the strength and stability of termite mounds. Environ Geotech 3(2):99-113

\section{Affiliations}

\section{R. Soar ${ }^{1}$ (D) . G. Amador ${ }^{2}$. P. Bardunias ${ }^{3}$. J. S. Turner ${ }^{4,5}$}

\author{
G. Amador \\ g.j.amador@tudelft.nl \\ P. Bardunias \\ pbardunias@fau.edu
}

J. S. Turner

jsturner@syr.edu

1 School of Architecture, Design and the Built Environment, Nottingham Trent University, Burton Street, Nottingham, UK
Lee S-H, Bardunias P, Su N-Y, Yang R-L (2008) Surface irregularity induced-tunnelling behavior of the Formosan subterranean termite. Behav Process 78:473-476

Loudon C, Koehl MA (2000) Sniffing by a silkworm moth: wing fanning enhances air penetration through and pheromone interception by antennae. J Exp Biol 203(19):2977-2990

Prandtl L (1904) Über Flüssigkeitsbewegung bei sehr kleiner Reibung. In: Krazer A (ed) Verhandlungen des dritten internationalen Mathematiker-Kongresses in Heidelberg 1904. Teubner, Leipzig, 484-491

Schlichting H (1960) Boundary-layer theory, 7. McGraw-Hill, New York

Schneider RW, Lanzen J, Moore PA (1998) Boundary-layer effect on chemical signal movement near the antennae of the sphinx moth, Manduca sexta: temporal filters for olfaction. J Comp Physiol A 182(3):287-298

Spalding DB (1954) Mass transfer in laminar flow. Proc R Soc Lond A Math Phys Sci 221(1144):78-99

Steinmann T, Casas J, Krijnen G (2006) Air-flow sensitive hairs: boundary layers in oscillatory flows around arthropod appendages. J Exp Biol 209:4398-4408

Tautz J (1989) Medienbewegung in der Sinneswelt des Arthropoden. Fallstudien zu einer Sinnesökologie, vol 6. Gustav Fischer Verlag, Stuttgart

Theraulaz G, Bonabeau E (1999) A brief history of stigmergy. Artif Life 5(2):97-116

Turner JS (2011) Termites as a model of swarm cognition. Swarm Intell 5(1):19-43

Vogel S (1983) How much air passes through a silkmoth's antenna? J Insect Physiol 29:597-602

Vogel S (2004) Living in a physical world I. Two ways to move material. J Biosci 29(4):391-397

Wang CY (2007) Similarity stagnation point solutions of the NavierStokes equations-review and extension. Eur J Mech B Fluids 27(6):678-683

Zachariah N, Das A, Murthy TG, Borges RM (2017) Building mud castles: a perspective from brick-laying termites. Sci Rep $7(1): 2045-2322$

Zhou Z, Han J (2013) Dynamics of Soil water evaporation during soil drying: laboratory experiment and numerical analysis. Sci World J. 2013:240280

Ziesmann J (1996) The physiology of an olfactory sensillum of the termite Schedorhinotermes lamanianus: carbon dioxide as a modulator of olfactory sensitivity. J Comput Physiol A 179:123-133

2 Laboratory for Aero and Hydrodynamics, Delft University of Technology, 2628 CD Delft, The Netherlands

3 Biological Science, Florida Atlantic University, Boca Raton, FL, USA

4 Department of Environmental \& Forest Biology, SUNY College of Environmental Science and Forestry, 133 Illick Hall, Syracuse 13210, New York, USA

5 Stellenbosch Institute for Advanced Study, Stellenbosch 7700, South Africa 